\title{
Citizen Well-Being and GDP: Toward More Appropriate Measures of Namibia's Success and Progress
}

\author{
Justine Braby \\ Progress Namibia TAS, Windhoek, Namibia \\ Jessica-Jane Lavelle \\ University of Cape Town \\ Johannes Mulunga \\ Young Achievers Empowerment Project, Windhoek, Namibia \\ Namene Nekwaya \\ Young Achievers Empowerment Project, Windhoek, Namibia \\ Fikameni Mathias \\ Young Achievers Empowerment Project, Windhoek, Namibia

\section{Angula Angula} \\ Young Achievers Empowerment Project, Windhoek, Namibia
}

\begin{abstract}
Developing nations like Namibia are aiming to industrialize much like developed nations and use the gross domestic product to measure their progress. However, this development path has been largely unsustainable. For Namibia to develop into a sustainable society, a different approach is needed. This study aimed to find entry points toward such an approach. Surveys were conducted in Windhoek, Namibia's capital, to measure human well-being. Generally, as is expected in a developing country, well-being correlated positively along the income line. However, the indicators did illustrate that a more holistic measure would go a long way toward more effective development planning in Namibia. This study provided an entry point from which further work will be undertaken.
\end{abstract}

Keywords: development, sustainability, indicators, survey, Namibia, developing

\section{Introduction}

It has become widely recognized that our current global development path is not taking us in the right direction (Constanza et al., 2014; Rogers et al., 2012; Steffen et al., 2015; Stiglits, Sen, \& Fitoussi, 2009; Whitby, Seaford, \& Berry, 2014). Vast numbers of people live in poverty, and those countries that are deemed successful according to our economic paradigm have major health problems (Compas, Jaser, Dunn, \& Rodriguez, 2012; Rogers et al., 2012), depression, and anxiety (Bromet et al., 2011; Streib, 2007). In addition, the globally dominant economic system dependent on industrialization is increasingly putting Earth, and its ecosystem goods and services, under untenable pressure, which has direct effects on human well-being (Constanza et al., 2014; Stiglits et al., 2009). 
Global leaders are now realizing that many of our biggest challenges-namely, climate change, soil losses and land degradation, biodiversity loss, food insecurity and water scarcity, poverty, and inequality, among others-are a result of the economic paradigm that we have constructed for society. Fixing them with a short-term one-at-a-time approach will only ever be symptomatic. As a result, on July 19, 2011, the United Nations General Assembly resolution 65/309 was adopted by consensus by the 193-member United Nations. As part of this resolution, the General Assembly invited member states to "pursue the elaboration of additional measures to better capture the importance of the pursuit of happiness and well-being in their development with a view to guiding their public policies" (United Nations General Assembly, 2011, p. 1). This was followed by an official launch on April 4, 2012, at the United Nations High-Level Meeting on Well-Being and Happiness: Defining a New Economic Paradigm (Musikanski, 2015).

Namibia is a developing country with the driest climate in sub-Saharan Africa. Namibia's Vision 2030 is for the country to be industrialized by the year 2030. However, it also states that this development must be sustainable, and the ultimate direction is toward the well-being of Namibia's citizens (Republic of Namibia, 2004). Measuring the progress of Namibia against the vision and its national development plans (NDPs) has been primarily based on the gross domestic product (GDP), and to a much lesser extent, the Human Development Index and Gini coefficient (which measures income equality; Republic of Namibia, 2004).

The GDP is the market value of all goods and services within a country in any given year. It has been governments' dominant measure to guide public policy, and has been used as a broad measure of human welfare globally, even though Simon Kuznets, the GDP architect and Nobel Peace Prize winner, himself said that it was dangerously inadequate as a measure of quality of life or well-being (Constanza et al., 2014). Two major issues exist with the measure of GDP as a progress indicator for society: (a) it is a single metric, and we live in a complex socioecological system where everything is interconnected, and (b) it interprets every expense as positive and does not distinguish welfare enhancing activities from welfare reducing activities (Constanza et al., 2014). Increased crime rates do not raise living standards but they raise GDP by increasing expenditure on security systems.

Natural disasters can boost GDP because they stimulate rebuilding, and the more people are sick or incarcerated, the more money is made (hence, there is more research on management of chronic illnesses than on finding cures or lifestyle health research). In addition, it does not take into account income distribution. A recent study has shown that $1 \%$ of the world's population has more wealth than the rest of the world combined, with just 62 individuals owning the same wealth as 2.6 billion people (Hardoon, Ayele, \& Fuentes-Nieva, 2016). GDP, on its own, is inadequate as a measure of quality of life and is now widely agreed upon as a misleading measure of national success (Constanza et al., 2014). However, promoting GDP growth continues to be the primary national policy goal globally.

Development policies need to shift to better account for real welfare and not merely GDP growth. As of 2011 , humans were using $135 \%$ of the resources that can be sustainably generated in 1 year (Helliwell, Layard, \& Sachs, 2013). Despite this, economic welfare at the global scale has not been improving since 1978 (Helliwell et al., 2013; Kubizewski et al., 2013). If we hope to achieve a sustainable and desirable future, we need to rapidly shift our policy focus away from maximizing production and consumption (GDP) and toward improving human well-being (Atkisson, 2012; Kubizewski et al., 2013). 
Namibia is now in the final throes of implementing its fourth NDP (2012/2013-2016/2017) with primary goals including high and "sustained" economic growth, employment creation, and increased income equality (Republic of Namibia, 2012). Namibia's real GDP growth is projected at 5\% for 2015 (Bank of Namibia, 2015), and it ranks 126 out of 188 countries on the Human Development Index (United Nations Development Programme, 2015). Remembering that economic development without social upliftment of all Namibians is meaningless, well-being indicators that are context specific to Namibians should ideally become the new yardstick on which we measure success and policy formulation in Namibia. The aim of this study was to find entry points into the more holistic measure for the success of a developing country like Namibia, including a range of indicators to measure welfare. In 2012, an experimental survey was conducted with a sample of Windhoek, Namibia, residents to take the first steps toward this aim.

\section{Approach and Methodology to Survey}

\section{The Approach}

The general approach to this study was fivefold. First, a small group was formed (the committee) to develop and implement the study. Second, a literature review of the current alternative national indicators of welfare and well-being globally was conducted. Third, training sessions were conducted with students to run the surveys. Fourth, the survey was conducted. Last, the results were collated, analyzed, and written up.

\section{Committee and Research}

The small committee consisted of young volunteers who all share a passion for their country and its citizens' well-being. Together, this group discussed the different options available regarding national domains and indicators, available time and resources, the methodology of the survey, and developing the questionnaire for the survey. This included intensive literature research and mentorships by international experts in formulating alternative national indicators (e.g., the Balaton Group). A good review of the alternative indicators of welfare is given in Constanza et al. (2014). Based on reviews and discussions among the committee, the Bhutan example (www.grossnationalhappiness.com) and Happiness Alliance (http://www.happycounts.org/) were chosen as the templates from which to work.

\section{The Survey}

After discussions on how to best provide for a cross section of Windhoek's demographic with the limited budget and available time, the chosen suburbs to survey were done along an assumed income line, namely Ludwigsdorf (high income); Windhoek West (middle income); and Hakahana, Okuryangava, and Shandumbala in Katutura (ranging low to middle income). Approximately 600 people were surveyed in total, and suburban variation depended on various factors, such as willingness to answer, number of surveyors, etc. Surveys were conducted between August and October 2012.

\section{Analysis}

The survey was adapted from Gross National Happiness Bhutan and the Happiness Alliance with modifications according to the Namibian context. These were discussed and agreed upon by the committee. Domains were based on Gross National Happiness Bhutan and included (a) state of 
mind; (b) health; (c) education, recreation, and culture; (d) community strength; (e) good governance and political freedom; (f) area and environment; (g) time balance; (h) material well-being; and (i) work. To evaluate each domain, several indicators were assigned (Table 1).

Table 1: Domains With Indicators and Relative Weightings

\begin{tabular}{|c|c|c|c|c|c|c|c|}
\hline \multirow{2}{*}{\multicolumn{2}{|c|}{ Domain }} & \multirow[b]{2}{*}{ Indicator } & \multicolumn{2}{|c|}{$\begin{array}{c}\text { Individual indicator } \\
\text { weight }\end{array}$} & \multirow{2}{*}{$\begin{array}{l}\text { Domain } \\
\text { weight }\end{array}$} & \multicolumn{2}{|c|}{ Total weight } \\
\hline & & & Percentage & Fraction & & Fraction & Decimal \\
\hline \multirow[t]{4}{*}{1} & State of mind & Life satisfaction & $40.0 \%$ & $2 / 5$ & $1 / 9$ & $2 / 45$ & .044444 \\
\hline & & Life purpose & $40.0 \%$ & $2 / 5$ & $1 / 9$ & $2 / 45$ & .044444 \\
\hline & & Positive emotion & $10.0 \%$ & $1 / 10$ & $1 / 9$ & $1 / 90$ & .011111011111 \\
\hline & & Negative emotion & $10.0 \%$ & $1 / 10$ & $1 / 9$ & $1 / 90$ & .011111011111 \\
\hline \multirow[t]{3}{*}{2} & Health & Health status & $33.3 \%$ & $1 / 3$ & $1 / 9$ & $1 / 27$ & .037037 \\
\hline & & Energy & $33.3 \%$ & $1 / 3$ & $1 / 9$ & $1 / 27$ & .037037 \\
\hline & & Ability & $33.3 \%$ & $1 / 3$ & $1 / 9$ & $1 / 27$ & .037037 \\
\hline \multirow[t]{2}{*}{3} & Time balance & Time enjoyment & $50.0 \%$ & $1 / 2$ & $1 / 9$ & $1 / 18$ & .055556 \\
\hline & & Pace & $50.0 \%$ & $1 / 2$ & $1 / 9$ & $1 / 18$ & .055556 \\
\hline \multirow[t]{5}{*}{4} & Community & Trust & $25.0 \%$ & $1 / 4$ & $1 / 9$ & $1 / 36$ & .027778 \\
\hline & & Unity & $25.0 \%$ & $1 / 4$ & $1 / 9$ & $1 / 36$ & .027778 \\
\hline & & Safety & $25.0 \%$ & $1 / 4$ & $1 / 9$ & $1 / 36$ & .027778 \\
\hline & & $\begin{array}{l}\text { Donation (time and } \\
\text { money) }\end{array}$ & $15.0 \%$ & $3 / 20$ & $1 / 9$ & $1 / 6060$ & .016667 \\
\hline & & $\begin{array}{l}\text { Support and } \\
\text { relationships }\end{array}$ & $10.0 \%$ & $1 / 10$ & $1 / 9$ & $1 / 90$ & .011111 \\
\hline \multirow[t]{3}{*}{5} & $\begin{array}{l}\text { Education, } \\
\text { recreation, }\end{array}$ & $\begin{array}{l}\text { Education } \\
\text { satisfaction }\end{array}$ & $33.3 \%$ & $1 / 3$ & $1 / 9$ & $1 / 27$ & .037037 \\
\hline & & $\begin{array}{l}\text { Recreation } \\
\text { satisfaction }\end{array}$ & $33.3 \%$ & $1 / 3$ & $1 / 9$ & $1 / 27$ & .037037 \\
\hline & & Cultural satisfaction & $33.3 \%$ & $1 / 3$ & $1 / 9$ & $1 / 27$ & .037037 \\
\hline \multirow[t]{4}{*}{6} & Area and & Access to services & $25.0 \%$ & $1 / 4$ & $1 / 9$ & $1 / 36$ & .027778 \\
\hline & & Access to housing & $25.0 \%$ & $1 / 4$ & $1 / 9$ & $1 / 36$ & .027778 \\
\hline & & $\begin{array}{l}\text { Access to } \\
\text { employment }\end{array}$ & $25.0 \%$ & $1 / 4$ & $1 / 9$ & $1 / 36$ & .027778 \\
\hline & & Natural environment & $25.0 \%$ & $1 / 4$ & $1 / 9$ & $1 / 36$ & .027778 \\
\hline \multirow[t]{5}{*}{7} & Good & Infrastructure & $20.0 \%$ & $1 / 5$ & $1 / 9$ & $1 / 45$ & .022222 \\
\hline & & $\begin{array}{l}\text { Responsive } \\
\text { governance }\end{array}$ & $20.0 \%$ & $1 / 5$ & $1 / 9$ & $1 / 45$ & .022222 \\
\hline & & Political freedom & $20.0 \%$ & $1 / 5$ & $1 / 9$ & $1 / 45$ & .022222 \\
\hline & & Corruption & $20.0 \%$ & $1 / 5$ & $1 / 9$ & $1 / 45$ & .022222 \\
\hline & & $\begin{array}{l}\text { Governance } \\
\text { performance }\end{array}$ & $20.0 \%$ & $1 / 5$ & $1 / 9$ & $1 / 45$ & .022222 \\
\hline \multirow[t]{2}{*}{8} & $\begin{array}{l}\text { Material well- } \\
\text { heino }\end{array}$ & Financial freedom & $50.0 \%$ & $1 / 2$ & $1 / 9$ & $1 / 18$ & .055556 \\
\hline & & Buying power & $50.0 \%$ & $1 / 2$ & $1 / 9$ & $1 / 18$ & .055556 \\
\hline \multirow[t]{2}{*}{9} & Work & Work satisfaction & $40.0 \%$ & $2 / 5$ & $1 / 9$ & $2 / 45$ & .044444 \\
\hline & & Work environment & $60.0 \%$ & $3 / 5$ & $1 / 9$ & $3 / 45$ & .066667 \\
\hline
\end{tabular}


Each of the nine domains was assigned equal weights of $1 / 9$, as each domain is considered to be equal in its intrinsic importance as a component of gross national happiness (Ura, Alkire, \& Zangmo, 2012). However, the 30 indicators within the domains were weighted according to public opinion, previous studies, and committee discussion. In five domains, the indicators within the domain were equally weighted (health; time balance; education, recreation, and culture; area and environment; good governance and political freedom). In the remaining four domains, indicators were assigned weightings between 10 and 60\% (Table 1). A sufficiency threshold was assigned to each indicator at a level that was considered "sufficient" for the majority of people (www.bhutanstudies.org.bt). The sufficiency thresholds are based on several inputs including international and national standards, normative judgements from consultative sessions, and previous studies. Thus, for each indicator, the percentage of people above and below sufficiency was calculated, following which the percentage of people above and below sufficiency for each domain was calculated. All suburbs were collectively analyzed as well as separately.

\section{Results and Discussion}

Of 600 questionnaires attempted during the survey, 480 were returned, and 417 were answered (Hakahana, 71; Okuryangava, 87; Shandumbala, 105; Windhoek West, 123; and Ludwigsdorf, 31). The overall sufficiency for all suburbs was $45.92 \%$. Sufficiency was reached in 12 indicators and two domains, namely, state of mind (66.46\%) and health (67.06\%; Table 2, Figure 1). For all suburbs, sufficiency was reached in these two domains. In Okuryangava, sufficiency was also achieved in education, recreation, and culture (58.13\%) and material well-being (53.04\%). In Windhoek West, area and environment achieved 59.23\% (Table 2, Figure 1). In Ludwigsdorf, material well-being (51.9\%) and work (50.96\%) were above sufficiency. In all suburbs, health status was the highest scoring indicator, while corruption and trust were the two lowest scoring indicators (Table 2, Figure 1). Hakahana achieved sufficiency in the least indicators (four) and had the lowest overall sufficiency at $35.27 \%$. Okuryangava had the highest (51.74\%), with sufficiency achieved in 17 indicators (Table 2, Figure 1).

Generally, well-being seemed to correlate along the income line, with the exception of Okuryangava (Table 3, Figure 2). Okuryangava is an informal settlement, and has a relatively high rate of poverty, rated second poorest community amongst the chosen suburbs. It is not surprising that in a country with a high income gap, and one that is still considered developing, that increasing income has an impact on increasing well-being. However, what is surprising is the exception that the sample members from Okuryangava had the highest state of well-being, despite being the second lowest in income. Discussions with residents of the community after these results were found, as well as discussions within the committee, yielded suggestions that perhaps, due to the historic demographic of the suburb (older community), residents are satisfied in comparison to the little freedom they had preindependence, illustrating signs of humility and perhaps lower expectations. 
Table 2: Summary of Sufficiency According to Suburb

\begin{tabular}{|c|c|c|c|c|c|c|c|}
\hline Suburb & $\begin{array}{c}\text { Overall } \\
\text { sufficiency }\end{array}$ & $\begin{array}{c}\text { Number of } \\
\text { domains above } \\
\text { sufficiency }\end{array}$ & $\begin{array}{c}\text { Number of } \\
\text { indicators above } \\
\text { sufficiency }\end{array}$ & $\begin{array}{l}\text { Highest } \\
\text { indicator }\end{array}$ & $\%$ & $\begin{array}{l}\text { Lowest } \\
\text { indicator }\end{array}$ & $\%$ \\
\hline Okuryangava & 51.74 & 4 & 17 & $\begin{array}{l}\text { Health } \\
\text { status }\end{array}$ & 94.10 & Corruption & 13.50 \\
\hline Ludwigsdorf & 50.9696 & 4 & 15 & $\begin{array}{l}\text { Health } \\
\text { status }\end{array}$ & $\begin{array}{c}93.40 \\
40\end{array}$ & Corruption & 3.20 \\
\hline $\begin{array}{l}\text { Windhoek } \\
\text { West }\end{array}$ & 50.00 & 3 & 16 & $\begin{array}{l}\text { Health } \\
\text { status }\end{array}$ & 92.50 & Corruption & 15.00 \\
\hline Shandumbala & 43.72 & 2 & 10 & $\begin{array}{l}\text { Health } \\
\text { status }\end{array}$ & 88.90 & Trust & 12.28 \\
\hline Hakahana & 35.27 & 2 & 4 & $\begin{array}{l}\text { Health } \\
\text { status }\end{array}$ & $\begin{array}{c}92.80 \\
80\end{array}$ & Trust & 8.75 \\
\hline
\end{tabular}

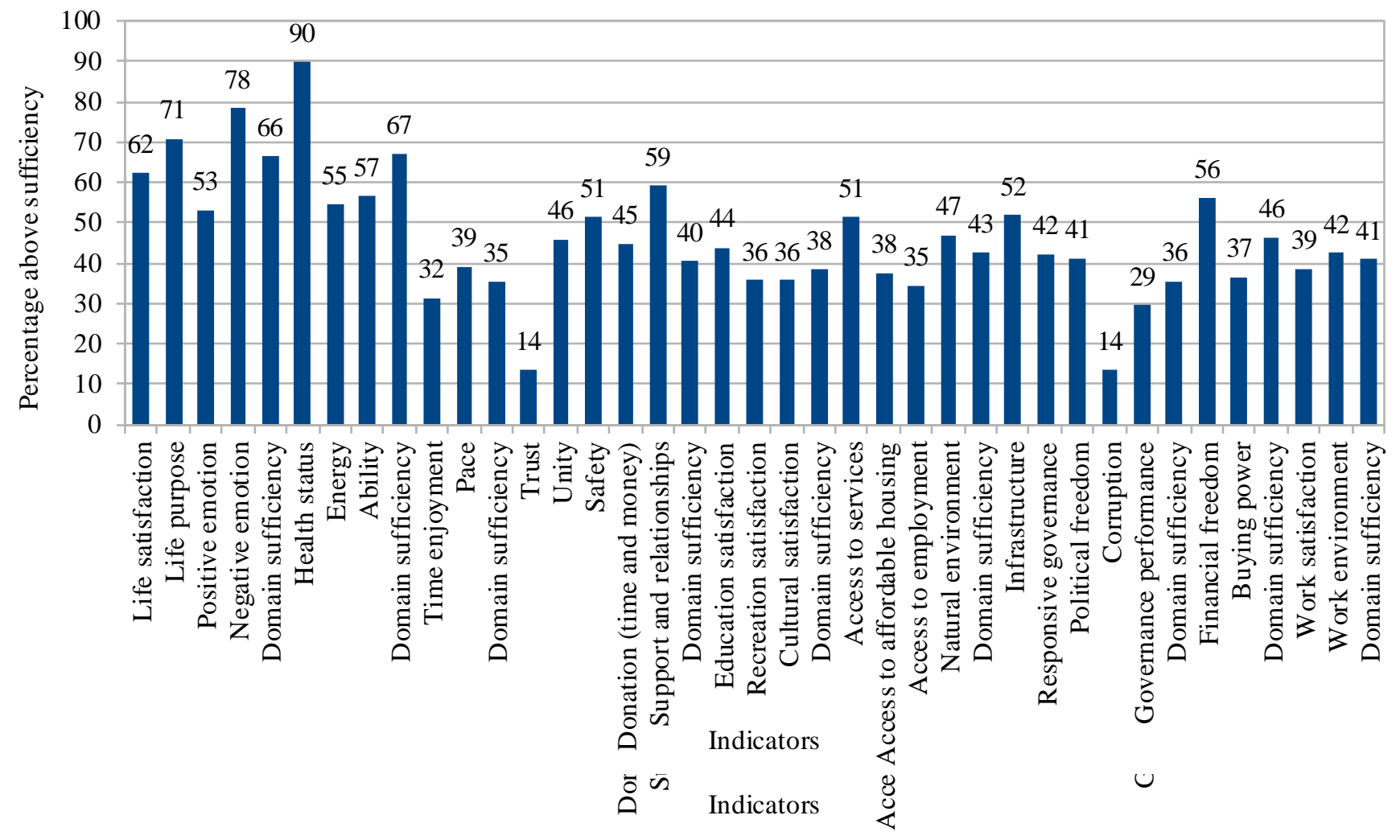

Figure 1: Percentage Above Sufficiency for All Indicators Including All Suburbs 
Table 3: Percentage Above Sufficiency for All Domains and Indicators According to Suburb

\begin{tabular}{|c|c|c|c|c|c|c|c|c|}
\hline & & & \multicolumn{6}{|c|}{ Percentage above sufficiency } \\
\hline \multicolumn{2}{|c|}{ Domain } & Indicator & All & Hakahana & Okuryangava & Shandumbala & $\begin{array}{c}\text { Windhoek } \\
\text { West }\end{array}$ & Ludwigsdorf \\
\hline \multirow[t]{5}{*}{1} & State of mind & Life satisfaction & 62.3535 & 41.50 & 79.55 & 62.2020 & 59.40 & 77.40 \\
\hline & & Life purpose & 70.92 & 58.28 & 74.44 & 73.72 & 70.84 & 80.6868 \\
\hline & & Positive emotion & 53.23 & 36.6565 & 57.43 & 52.60 & 58.75 & 75.00 \\
\hline & & Negative emotion & 78.28 & 73.70 & 78.78 & 80.10 & 78.98 & 85.32 \\
\hline & & Domain sufficiency & 66.46 & 50.95 & 75.22 & 67.64 & 66.87 & 79.26 \\
\hline \multirow[t]{4}{*}{2} & Health & Health status & 89.90 & 92.8080 & 94.10 & 88.90 & 92.50 & 93.40 \\
\hline & & Energy & 54.63 & 40.50 & 55.23 & 54.00 & 56.27 & 78.50 \\
\hline & & Ability & 56.65 & 49.30 & 66.00 & 50.05 & 58.60 & 70.95 \\
\hline & & Domain sufficiency & 67.0606 & 60.87 & 71.78 & 64.32 & 69.12 & 80.95 \\
\hline \multirow[t]{3}{*}{3} & Time balance & Time enjoyment & 31.50 & 25.70 & 37.90 & 38.5050 & 29.20 & 32.30 \\
\hline & & Pace & 39.18 & 30.90 & 43.45 & 44.6868 & 42.00 & 22.55 \\
\hline & & Domain sufficiency & 35.3434 & 28.30 & 40.68 & 41.5959 & 35.60 & 27.43 \\
\hline \multirow[t]{6}{*}{4} & Community & Trust & 13.58 & 8.75 & 17.23 & 12.28 & 16.38 & 19.35 \\
\hline & & Unity & 46.03 & 38.47 & 51.70 & 46.87 & 41.37 & 37.63 \\
\hline & & Safety & 51.40 & 32.80 & 60.00 & 51.50 & 60.30 & 51.60 \\
\hline & & Donation (time and money) & 44.75 & 45.75 & 33.80 & 43.60 & 51.20 & 66.15 \\
\hline & & Support and relationships & 59.10 & 45.67 & 65.37 & 56.27 & 61.90 & 71.90 \\
\hline & & Domain sufficiency & 40.37 & 31.43 & 43.84 & 39.83 & 43.38 & 44.26 \\
\hline \multirow[t]{4}{*}{5} & Education, & Education satisfaction & 43.9393 & 37.13 & 50.20 & 44.67 & 53.27 & 19.37 \\
\hline & & Recreation satisfaction & 35.70 & 20.00 & 62.10 & 27.90 & 36.40 & 42.00 \\
\hline & & Cultural satisfaction & 35.70 & 20.00 & 62.10 & 27.90 & 36.40 & 42.00 \\
\hline & & Domain sufficiency & 38.44 & 25.71 & 58.13 & 33.49 & 42.02 & 34.4646 \\
\hline 6 & $\begin{array}{l}\text { Area and } \\
\text { environment }\end{array}$ & Access to services & 51.30 & 36.93 & 56.90 & 47.23 & 68.87 & 40.00 \\
\hline
\end{tabular}




\begin{tabular}{|c|c|c|c|c|c|c|c|c|}
\hline & & & & & Percentage & bove sufficiency & & \\
\hline & main & Indicator & All & Hakahana & Okuryangava & Shandumbala & $\begin{array}{c}\text { Windhoek } \\
\text { West }\end{array}$ & Ludwigsdorf \\
\hline & & Access to housing & 37.60 & 28.80 & 45.20 & 36.90 & 47.50 & 25.80 \\
\hline & & Access to employment & 34.5050 & 20.8080 & 32.20 & 30.10 & 49.20 & 45.20 \\
\hline & & Natural environment & 47.07 & 26.6666 & 37.87 & 44.54 & 71.34 & 59.49 \\
\hline & & Domain sufficiency & 42.6262 & 28.3030 & 43.04 & 39.69 & 59.23 & 42.62 \\
\hline 7 & Good governance & Infrastructure & 51.80 & 26.10 & 51.80 & 53.40 & 62.70 & 74.20 \\
\hline & & Responsive governance & 42.25 & 27.7070 & 55.85 & 36.20 & 46.70 & 31.30 \\
\hline & & Political freedom & 41.20 & 24.60 & 49.40 & 38.40 & 55.50 & 30.00 \\
\hline & & Corruption & 13.60 & 13.0000 & 13.50 & 18.10 & 15.00 & 3.20 \\
\hline & & Governance performance & 29.45 & 22.05 & 27.15 & 29.60 & 38.75 & 16.15 \\
\hline & & Domain sufficiency & 35.66 & 22.69 & 39.54 & 35.14 & 43.73 & 30.97 \\
\hline 8 & Material well- & Financial freedom & 56.1010 & 57.70 & 65.75 & 48.95 & 57.35 & 48.50 \\
\hline & & Buying power & 36.7070 & 33.87 & 40.33 & 28.70 & 41.47 & 55.30 \\
\hline & & Domain sufficiency & 46.040 & 45.78 & 53.04 & 38.83 & 49.41 & 51.90 \\
\hline 9 & Work & Work satisfaction & 38.63 & 21.7070 & 40.00 & 27.90 & 40.80 & 67.83 \\
\hline & & Work environment & 42.43 & 24.50 & 40.70 & 36.40 & 42.20 & 66.10 \\
\hline & & Domain sufficiency & 40.91 & 23.38 & 40.42 & 33.00 & 41.64 & 66.79 \\
\hline & & Overall sufficiency & 45.92 & 35.27 & 51.74 & 43.7272 & 50.00 & 50.96 \\
\hline
\end{tabular}




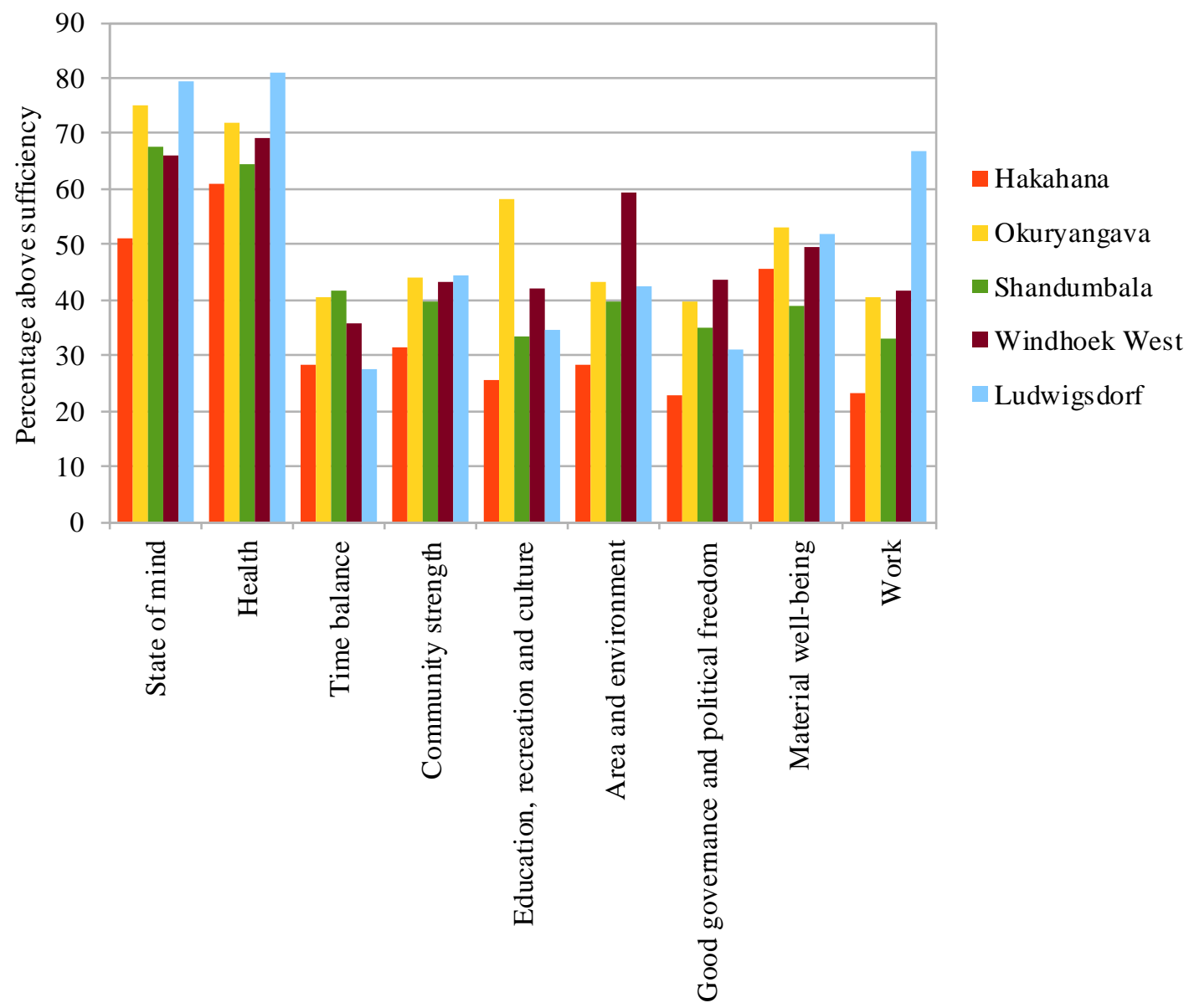

Domain

\section{Figure 2: Percentage Above Sufficiency for Each Domain According to Suburb}

Generally, across the entire survey sample, state of mind (i.e., satisfaction with life and life purpose, as well as emotional stability) was sufficient, as was personal health (health status, energy, and ability; Table 3, Figure 1).

Generally, respondents felt that they did not have enough free time (Figure 1). This is connected to time/work balance. Work satisfaction as well as the work environment (e.g., appropriate pay, productivity, level of freedom for creativity) was generally low in all suburbs except Ludwigsdorf.

Community strength and a sense of belonging to a community are immensely important components of well-being in human society. According to our study, sense of community strength was lowest in the highest income area, Ludwigsdorf, and highest in the Katutura suburbs in general (i.e., Shandumbala, Okuryangava, and Hakahana; Table 3, Figure 2). Sense of security and safety was lowest in Hakahana, possibly linked to lack of trust, low income, and high poverty rates (resulting in desperation leading to crime), high unemployment, and a lack of trust by the community in general. 
The education, recreation, and culture domain was rated low in all suburbs, although Okuryangava rated above sufficiency in this domain (Table 3, Figure 2). People, generally, felt that they did not have access to proper education, informal education facilities, recreational activities, and facilities. It is assumed that lack of access might be due to lack of infrastructure and opportunities. However, some access issues might be a result of a lack of awareness or knowledge of available and existing opportunities.

Access to basic services reached sufficiency in only two of the suburbs (Okuryangava and Windhoek West; Table 3, Figure 2). Ludwigsdorf respondents were below sufficiency even though the entire community has direct access to water and electricity, for instance. However, the low sufficiency might be associated with higher costs for these services as opposed to the lack of them.

In the suburbs of Katutura, people felt that the natural environment was badly maintained, with Windhoek West and Ludwigsdorf above sufficiency. Community citizen projects could improve the natural environment of Katutura (such as, for instance, antilittering campaigns, community park creations, and access to recycling services).

Unsurprisingly, access to employment was below sufficiency, and, indeed, one of the greater challenges (Figure 2). This is already an addressed challenge in our NDPs as well as more direct work done by the Namibian planning commission (such as the Targeted Intervention Programme for Employment and Economic Growth) and the recent ministerial reshuffle leading to one of the ministries being now named Ministry of Labour, Industrial Relations, and Employment Creation.

Good governance and political freedom was perhaps the most challenging domain (Table 2, Figure 2). Generally, respondents were content with existing infrastructure, with the exception of Hakahana (an informal settlement with very little access to basic services). All suburbs with the exception of Okuryangava felt that their government was not responsive enough. All suburbs, except Windhoek West (middle-income suburb), were below sufficiency regarding political freedom. Corruption was generally found to be the biggest problem and lowest indicator by the respondents. Governance performance was also ranked very low in all suburbs.

Generally, respondents felt that they had financial freedom (i.e., being able to pay minimal bills and feed themselves; Figure 2). Buying power (i.e., paying for desired versus required items), however, was low in all suburbs except Ludwigsdorf (Table 3).

\section{Conclusions and Way Forward}

\section{Shortcomings and Lessons Learned From the Entry Point Study}

Overall, the study was limited by funding and available human resources (all of which were voluntary). Restrictions had to be made to keep in line with the small budget, and often, additional money was sourced privately to pay for services and materials. Volunteerism was strong, and the committee was passionate and put forward immense effort given the amount of other commitments.

There were many lessons learned throughout the process of this entry point initiative. These came from two separate angles, namely, (a) through the methods and approach we tested and (b) feedback from the survey participants. 
The questionnaire had a section in which participants could give comments and feedback. Most of the participants claimed that the questionnaire was too long, with many repetitive questions. Some felt that the questions were too personal. A few entrants made demands, such as the need for housing, closing down of shebeens (informal bars), more jobs, and better access to education, among others. One or two participants claimed they should receive money for answering the questionnaire, and some asked that something be done for them based on their answers. Most participants who entered feedback gave appreciation toward the effort of the survey and overall initiative.

The feedback from participants, coupled with our own lessons learned, has culminated in a few important lessons for the way forward:

1. The questionnaire was too long and there were unnecessary duplications, with too many options. In addition, it was complicated for some people. We will need to shorten and simplify the questionnaire, with translations into vernacular languages.

2. The door-to-door process worked in some areas, but not in others. For instance, in Ludwigsdorf, it was very difficult to even have the door answered, and, often, we were turned away. In addition, those who did accept to answer the questionnaire (only after telling them that they could do it on their own time and we would collect after a given number of days) were then not home or could not be contacted to retrieve the answered questionnaire. It may have been easier to have used another method of survey for this area-through e-mail or an Internet link. This was initially discussed, but again, funding limited further action. I other areas, where Internet access is not available, the door-to-door process was the most appropriate approach-but was also not an ideal situation.

\section{Toward a More Appropriate and Holistic Measure}

This study is the entry point into investigating more holistic measures for the success and prosperity of Namibia. We hope that this work sparks an important debate on the future of indicators for wellbeing and success in Namibia and mobilizes thought processes in at least local development planning for Windhoek. Another aim of this work was to allow for an entry point for further study and work in this arena. This small entry point study was merely a first step and a learning process to inform future and more detailed studies and resulting action in Namibian communities for the eventual inclusion of such information and indicators into our national planning systems, such as the coming NDPs. The next step would be to take the results back to a survey community and discuss, with the community and the city of Windhoek, how one could improve the status of the community. In addition, fine-tuning the domains, indicators, and survey questions based on feedback from this study, and furthering it into other parts of Namibia, would give a good baseline of the current state of overall well-being, happiness, and contentment (and the contextualized definitions thereof) of Namibian citizens living in different communities. The final step would be to hone in on the results and determine where improvements can be made by government in partnership with communities, the private sector, nongovernmental organizations, and community-based organizations, with a sound feedback mechanism that is people-centered. 


\section{References}

Atkisson, A. (2012). Life beyond growth: Alternatives and complements to GDP-measured growth as a framing concept for social progress: 2012 annual survey report of the Institute for Studies in Happiness, Economics and Society - ISHES (Tokyo, Japan). Oxford, England: The Isis Academy.

Bank of Namibia. (2015, July). Economic outlook. Retrieved from https://www.bon.com.na/CMSTemplates/Bon/Files/bon.com.na/04/04922910-1b4c-4fe4-bb 3b88595db1f214. pdf

Bromet, E., Andrade, L. H., Hwang, I., Sampson, N. A., Alonso, J., de Girolamo, G., ... . Kessler, R. C. (2011). Cross-national epidemiology of DSM-IV major depressive episode. BMC Medicine, 9, 90. doi: 10.1186/1741-7015-9-90

Compas, B. E., Jaser, S. S., Dunn, M. J., \& Rodriguez, E. M. (2012). Coping with chronic illness in childhood and adolescence. Annual Review of Clinical Psychology, 8, 455-480.

Constanza, R., Kubiszewski, I., Giovannini, E., Lovins, H., McGlade, J., Pickett K. E., ... Wilkinson R. (2014). Time to leave GDP behind. Nature, 505, 283-285.

Hardoon, D., Ayele, S., \& Fuentes-Nieva, R. (2016). An economy for the 1\%: How privilege and power in the economy drive extreme inequality and how this can be stopped. Oxford, UK: Oxfam International. Retrieved from https://www.oxfam.org/sites/www.oxfam.org/files/file_attachments/bp210-economy-onepercent-tax-havens-180116-en_0.pdf

Helliwell, J., Layard, R., \& Sachs, J. (Eds.). (2013) The World Happiness Report 2013. New York, NY: U.N. Sustainable Development Solutions Network. Retrieved from http://unsdsn.org/wpcontent/uploads/2014/02/WorldHappiness Report2013_online.pdf

Kubizewski, I., Constanza, R., Franco, C., Lawn, P., Talberth, J., Jackson, T., \& Aylmer, C. (2013). Beyond GDP: Measuring and achieving global genuine progress. Ecological Economics, 93, $57-68$.

Musikanski, L. (2015). Measuring happiness to guide public policy making: A survey of instruments and policy initiatives. Journal of Social Change, 7, 39-55.

Republic of Namibia. (2004). Vision 2030: Policy Framework for long-term national development. Windhoek, Namibia: Author. Retrieved from http://www.met.gov.na/Documents/Vision\%202030.pdf

Republic of Namibia. (2012). Namibia's Fourth National Development Plan (NDP4): 2012/13 to 2016/17: “Changing gear towards Vision 2030." Windhoek, Namibia: Author. Retrieved from http://www.npc.gov.na/?wpfb_dl=37

Rogers, D. S., Duraiappah, A. K., Antons, D. C., Munoz, P., Bai, X., Fragkias, M., \& Gutscher, H. (2012). A vision for human well-being: Transition to social sustainability. Environmental Sustainability, 4, 1-13.

Steffen, W., Richardson, K., Rockström, J., Cornell, S. E., Fetzer, I., Bennet, E. E., . . Sörlin, S. (2015). Planetary boundaries: Guiding human development on a changing planet. Science, 347, 6223. doi: 10.1126/science. 1259855 
Stiglits, J., Sen, A., \& Fitoussi J. P. (2009). Report by the Commission on the Measurement of Economic Performance and Social Progress. Retrieved from http://www.communityindicators.net/system/publication_pdfs/9/original/Stiglitz_Sen_Fitouss i_2009.pdf?1323961027.

Streib, L. (2007). World's fattest countries. Forbes. Retrieved from http://www.forbes.com/2007/02/07/worlds-fattest-countries-forbeslife-cx_ls_0208worldfat.html

United Nations Development Programme. (2015). Namibia Country Notes: Work for human development: Briefing note for countries on the 2015 Human Development Report. Retrieved from http://hdr.undp.org/sites/all/themes/hdr_theme/country-notes/NAM.pdf

United Nations General Assembly. (2011, July 11). Resolution adopted by the General Assembly on 19 July 2011, 65/309. Happiness: towards a holistic approach to development. Retrieved from http://www.un.org/en/ga/search/view_doc.asp?symbol=A/RES/65/309

Ura, K., Alkire, S., \& Zangmo, T. (2012). GNH and GNH Index. Thimphu, Bhutan: Centre for Bhutan Studies. Retrieved from http://www.ophi.org.uk/wp-con tent/uploads/Ura-et-alBhutan-Happiness-Chapter.pdf

Whitby, A., Seaford, C., Berry, C., \& BRAINPOoL Consortium Partners. (2014, March 31). BRAINPOoL Project final report: Beyond GDP: From measurement to politics and policy. BRAINPOoL Deliverable 5.2, A collaborative programme funded by the European Union's Seventh Programme for research, technological development and demonstration under Grant Agreement No. 283024. World Future Council. Retrieved from http://www.brainpoolproject.eu/wp-content/u ploads/2014/05/BRAINPOoL-Project-FinalReport.pdf

The Journal of SocialChange, sponsored by Walden University, welcomes manuscripts focusing on interdisciplinary research in social change that improves the human condition and moves people, groups, organizations, cultures, and society toward a more positive future.

Walden University Publishing: http://www.publishing.waldenu.edu 